\title{
Predisposing Factors and Aetiologic Diagnosis of Infectious Corneal Ulcer
}

\author{
Sharmeen Ahmed ${ }^{1}$, Anamica Ghosh ${ }^{1}$, Syed A Hassan ${ }^{2}$, Shirin Tarafder ${ }^{1}$, Md. Ruhul Amin Miah ${ }^{1}$ \\ ${ }^{1}$ Department of Microbiology \& Immunology, Bangabandhu Sheikh Mujib Medical University, Dhaka; ${ }^{2}$ Department of Cornea, \\ Islamia Eye Hospital, Dhaka.
}

\begin{abstract}
This cross-sectional study was carried out to identify causative pathogens and to determine the demographic characteristics and predisposing factors of corneal ulcer presenting at tertiary care hospitals in Dhaka. A total of 250 samples (corneal swab and scrapings) were collected from clinically diagnosed corneal ulcer patients attending Bangabandhu Sheikh Mujib Medical University and Islamia Eye Hospital from February, 2004 to January, 2005. Out of 250 samples, microbial infection was established in $147(58.8 \%)$ cases by culture and microscopy in which $82(32.8 \%)$ patients showed fungal growth, $52(20.8 \%)$ cases had bacterial growth and 13 (5.2\%) cases had mixed bacterial \& fungal growth. Aspergillus species $48(50.53 \%)$ were the most common fungal isolates followed by Fusarium species 25 (26.32\%). The predominant bacterial isolates were Staphylococcus epidermidis 22(32.85\%) followed by Staphylococcus aureus 17 (26.15\%) and Pseudomonas species $13(20 \%)$. Out of 147 cases a larger group of patients $(105,71.43 \%)$ were in middle age group $(21$ to 50 years). Males $(95,64.63 \%)$ were more often affected $(\mathrm{P}<0.001)$. A majority of patients $(\mathbf{1 1 4}, \mathbf{7 7 . 5 5 \% )}$ came from rural areas $(\mathrm{P}<\mathbf{0 . 0 0 1})$, and most patients $(\mathbf{5 5}, \mathbf{3 7 . 4 1 \% )}$ of bacterial \& fungal keratitis were farmers. Ocular trauma $(87,59.18 \%)$ was a highly significant risk factor $(\mathrm{P}<0.001)$ of which mostly $(41,27.89 \%)$ were due to agricultural materials. The findings of this study would help the ophthalmologists in the management of their patients with keratitis.
\end{abstract}

Keywords: Corneal Ulcer, Infective Keratitis, Predisposing factors.

\section{Introduction:}

Corneal ulcer is a potentially sight threatening ocular condition and the leading cause of monocular blindness in developing countries. ${ }^{1,2}$ Infectious keratitis can be caused by various pathogens i.e, bacteria, fungi, virus and parasites. In a study conducted in Chittagong, Bangladesh, 53.5\% bacteria and $39.9 \%$ fungi were found as microbial aetiology of corneal ulcer. $^{3}$ The incidence of fungal keratitis $(42.86 \%)$ was higher than bacterial keratitis (25\%) in Rajshahi, northern part of Bangladesh. ${ }^{4}$ Aetiologic and epidemiologic pattern of corneal ulceration varies with the patient population, geographic location and climate and it tends to vary somewhat over

\section{Correspondence:}

Dr. Sharmeen Ahmed

Associate Professor

Department of Microbiology and Immunology

Bangabandhu Sheikh Mujib Medical University, Dhaka

Email: sharmeenahmed@bsmmu.org

Contact: (+88) 01819216919 time. ${ }^{5}$ Infectious corneal ulcer is associated with some predisposing factors. Ocular trauma is a far more common predisposing factor of infectious keratitis in developing countries, whereas pre-existing ocular disease and contact lens are common risk factors in developed countries. ${ }^{6,7}$ Hence, an understanding of the aetiologic agents, epidemiologic features and risk factors that occur in specific region are important in rapid recognition, timely institution of therapy, optimal management and prevention of disease entity.

The purpose of the study was to identify causative pathogens and to determine the predisposing factors of corneal ulcer of patients attending tertiary care hospitals in Dhaka, Bangladesh.

\section{Method}

A total of 250 clinically diagnosed patients of corneal ulcer who attended the outpatient departments of Bangabandhu Sheikh Mujib Medical University (BSMMU) and Islamia Eye Hospital from February, 2004 to January, 2005 were enrolled 
in this cross sectional study. A complete case history with necessary information for each patient was recorded in predesigned data sheet.

One corneal swab and three corneal scrapings were collected from each patient by an opthalmologist with all aseptic precautions. Corneal swab was taken by rubbing the ulcerated area of the cornea with sterile cotton swab soaked with sterile normal saline before instillation of local anaesthetic. ${ }^{8}$ Corneal scrapings were taken from leading edge and base of ulcer using Bard-Parker blade (No. 15) after instillation of $0.4 \%$ oxybuprocain without preservative. The material scraped was initially spread onto a labelled slide to prepare a $10 \%$ potassium hydroxide $(\mathrm{KOH})$ wet mount. The second scraped material was directly inoculated onto sabouraud's dextrose agar media in a row of C-shaped Streaks. And the last scraping was used to prepare a smear for Gram staining. ${ }^{9-11}$

The swab was inoculated onto Saboraud's dextrose agar (SDA), blood agar, MacConkey's agar and chocolate agar media and incubated aerobically at $37^{\circ} \mathrm{C}$ for 48 hours. Chocolate agar was incubated in candle extinction jar to ensure $5-10 \% \mathrm{CO}_{2}$. All labaratory methods followed standard protocols. ${ }^{9-11}$ Bacterial culture were considered significant if growth of an organism was demonstrated on more than one media and/or if there was confluent growth at the site of inoculation on one medium, and/or if growth of one medium consistent with direct microscopy findings. ${ }^{9-11}$ Inoculated sabouraud's dextrose agar medium was incubated at $25{ }^{\circ} \mathrm{C}$ and observed daily for the first 7 days and on alternate days for the next 7 days, for observing slow growing fungi. Identification of fungal growth finally was done based on its macroscopic and microscopic features. ${ }^{12}$ Pearson's chi-square test was used for the statistical analysis wherever required.

\section{Results:}

Out of 250 samples (Corneal swab \& scrapings) of clinically diagnosed corneal ulcer, microbial infection was established in $147(58.8 \%)$ cases by culture and microscopy at Microbiology laboratory of BSMMU. Out of 250 cases, $82(32.8 \%)$ patients showed fungal growth, $52(20.8 \%)$ patients had bacterial growth and $13(5.2 \%)$ had mixed bacterial and fungal growth. Patterns of isolated fungi and bacteria are shown in figure 1 and figure 2 respectively. Aspergillus species $48(50.53 \%)$ were the most common fungal isolates followed by Fusarium species 25 (26.32), Mucor spp. 8 (8.42\%), Rhizopus spp. $4(4.21 \%)$ and Alternaria spp. 4 (4.21\%). The predominant bacterial isolates were Staphylococcus epidermidis $(22,32.85 \%)$ followed by Staphylococcus aureus $(17,26.15 \%)$ and Pseudomonas species $(13,20 \%)$.

Out of 147 cases, a larger group of patients (105, 71.43\%) were between the ages 21 to 50 years. Males $(95,64.63 \%)$ were affected more often $(\mathrm{P}<0.001)$ with male to female ratio being 1.8:1. Most of the patients $(114,77.55 \%)$ were from rural areas $(\mathrm{P}<0.001)$ and fungal corneal ulcer was found significantly higher in rural population than urban $(\mathrm{P}<0.05)$ [Table-1]. A majority of patients $(55,37.41 \%)$ with fungal \& bacterial corneal ulcer were farmers $(\mathrm{P}<0.001)$ as compared to other occupation (Figure-3). The second common group of patients were housewives with predominating fungal keratitis. Corneal trauma was identified as predisposing factor in $87(59.18 \%$ ) patients of which $41(27.89 \%)$ were agricultural injuries, 30(20.4\%) were domestic and $16(10.88 \%)$ were dust injuries [Table-2]. The correlation between trauma and fungal keratitis was highly significant $(\mathrm{P}<0.001)$.

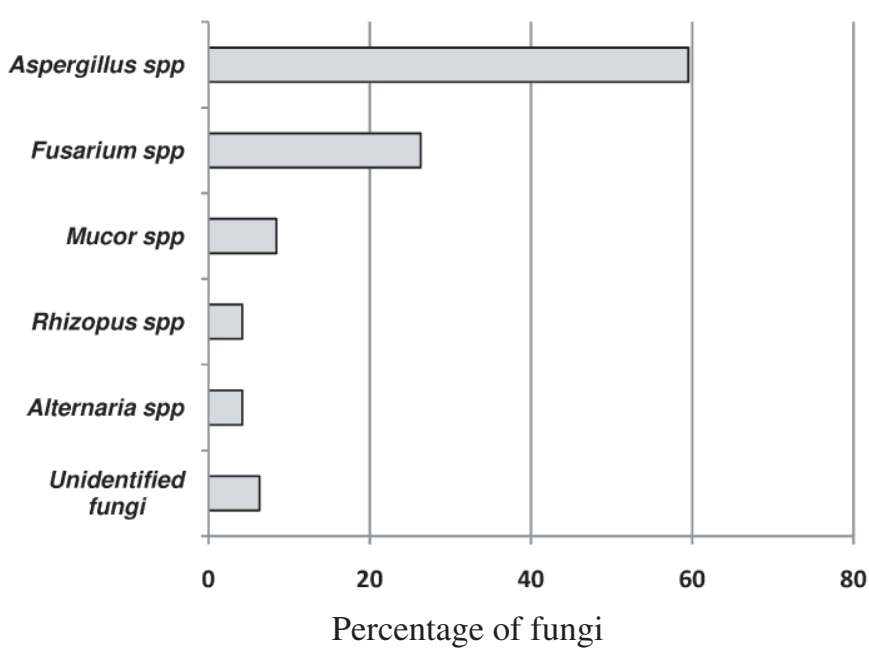

Figure 1 Relative Frequencies of isolated fungi

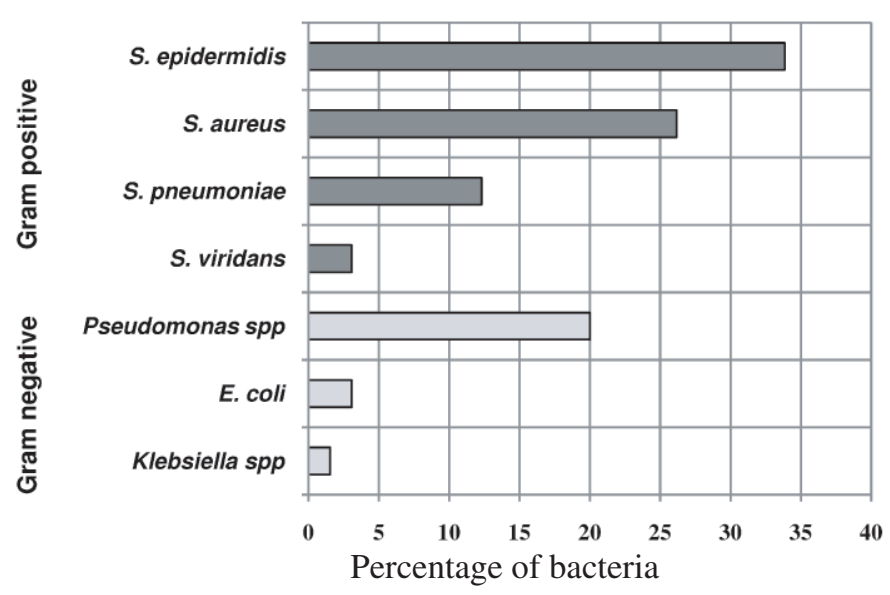

Figure 2 Relative frequencies of bacterial isolates 


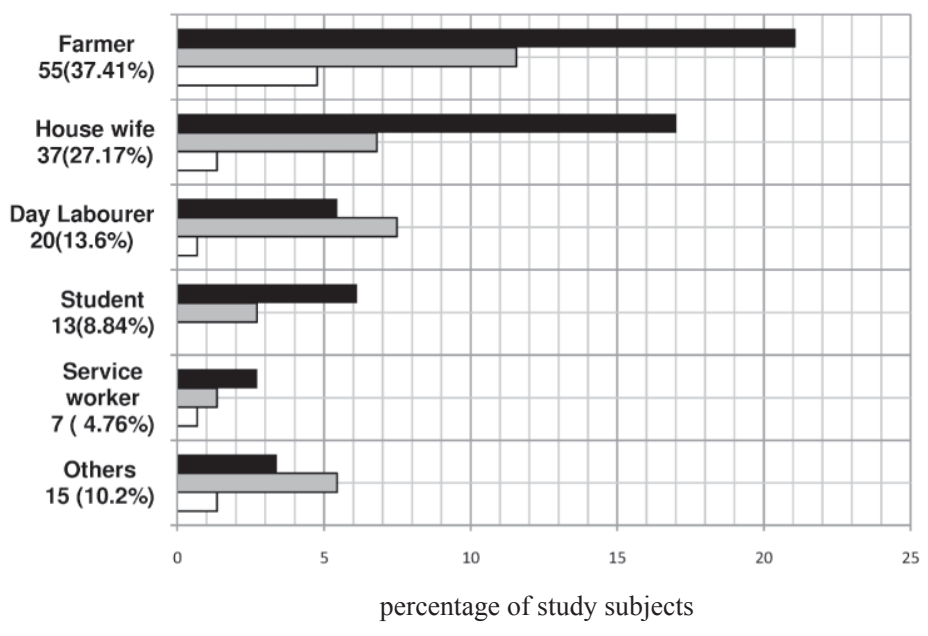

No. of fungus

$\square$ No. of bacteria

$\square$ No. of fungus and bacteria

Figure 3 Fungal and bacterial keratitis in different occupations of study population $(\mathrm{n}=147)$

Table-1. Distribution of infectious Keratitis in urban and rural population $(\mathrm{n}=147)$.

\begin{tabular}{lcccc}
\hline Residence & $\begin{array}{c}\text { Fungal Keratitis } \\
\mathrm{n}(\%)\end{array}$ & $\begin{array}{c}\text { Bacterial } \\
\text { Keratitis } \\
\mathrm{n}(\%)\end{array}$ & $\begin{array}{c}\text { Bacteria \& } \\
\text { Fungus Mixed } \\
\text { Keratitis n(\%) }\end{array}$ & Total (\%) \\
\hline Rural & $68(46.26)$ & $34(23.13)$ & $12(8.16)$ & $114(77.55)$ \\
Urban & $14(9.52)$ & $18(12.25)$ & $1(0.68)$ & $33(22.45)$
\end{tabular}

Table-2. Predisposing factors associated with fungal and bacterial corneal ulcer $(n=147)$.

\begin{tabular}{lllll}
\hline Predisposing factor & $\begin{array}{l}\text { Fungal } \\
\text { keratitis } \\
\mathrm{n}(\%)\end{array}$ & $\begin{array}{l}\text { bacterial } \\
\text { keratitis } \\
\mathrm{n}(\%)\end{array}$ & $\begin{array}{l}\text { Mixed (bacterial } \\
\text { fungal) keratitis } \\
\mathrm{n}(\%)\end{array}$ & Total (\%) \\
\hline Traumatic & $55(67.07)$ & $27(51.92)$ & $5(38.46)$ & $87(59.18)$ \\
$\quad$ Agricultural & 29 & 9 & 3 & $41(27.89)$ \\
$\quad$ Domestic & 18 & 10 & 2 & $30(20.40)$ \\
$\quad$ Dust injury & 8 & 8 & 0 & $16(10.88)$ \\
Ocular Diseases & $3(3.69)$ & $7(13.46)$ & $1(7.69)$ & $11(7.48)$ \\
Ocular surgery & $2(2.44)$ & $3(5.77)$ & 0 & $5(3.40)$ \\
Systemic diseases & $1(1.22)$ & 0 & 0 & $1(0.68)$ \\
Contact lens & 0 & $1(1.92)$ & 0 & $1(0.68)$ \\
Spontaneous & $21(25.61)$ & $14(26.92)$ & $7(53.85)$ & $42(28.57)$ \\
Total & $82(100)$ & $52(100)$ & $13(100)$ & $147(100)$ \\
\hline
\end{tabular}

\section{Discussion}

The study was designed to identify specific pathogenic agents and to determine demographic characteristics and predisposing factors of corneal ulcer patients attending tertiary care hospitals in Dhaka. Microorganisms were isolated in $147(58.8 \%)$ of the 250 cases of suspected infectious keratitis. This figure is close to many other reports ${ }^{11,13}$ but is lower than the reports from Nepal ${ }^{14}(80 \%)$ and from Bangladesh (81.7\%). 3,11,13,14 The prior antimicrobial therapy probably has a significant role in low yield in culture. ${ }^{11}$ In this study $32.8 \%$ patients had fungal growth, $20.8 \%$ patients were bacterial growth and $5.2 \%$ patients had mixed bacterial and fungal growth. These findings are similar to those of reports from several studies in India ${ }^{6,11}$. In contrast, Dunlop et al. ${ }^{3}$ isolated $53.5 \%$ bacteria and $35.9 \%$ fungi in their study conducted in Chittagong Eye Infirmary in Bangladesh. Aetiological pattern of corneal ulceration varies with geographic region, climate and tends to vary over time. ${ }^{5}$ In this study Aspergillus species (48, 50.53\%) were the most common fungal isolates followed by Fusarium species $25(26.32 \%)$. Aspergillus spp. were the most predominant fungal pathogens in the temperate regions of northern India Nepal and Bangladesh. 3,14,15 The predominant bacterial isolates were Staphylococcus epidermidis (22, 32.85\%) followed by staphylococcus aureus (17, 26.15\%) and Pseudomonas spp (13, 20\%). A review of literature showed that most of the studies from developed countries listed Staphylococcus epidermindis as the leading cause of bacterial keratitis. ${ }^{7,16}$ Considering the fact that Staphylococcus epidermidis and aureus form the commensal of extraocular surfaces, it is probable that these organisms invade corneal tissues when compromised by antimicrobial and/ or corticosteroid therapy or trauma.

A larger group of pateints of bacterial and fungal keratitis were of ages 21 to 50 years. This is similar to fungal keratitis that affects middle age group (21-50 years). ${ }^{11}$ The 1.8:1 male: female ratio in this study was similar to the ratio in a study in India. ${ }^{11}$ Considering the predominant predisposing factor of trauma in all type of microbial keratitis (bacterial- $67.07 \%$ and fungal $51.92 \%$ ), the probable reason for middle aged male preponderance is obvious in this study. Ocular trauma (agricultural and domestic injuries) was more associated with outdoor occupation. Among different occupation of study population, majority of patients $(37.41 \%)$ were farmers, followed by housewives (27.17\%), day labourers $(13.6 \%)$, students $(8.84 \%)$ and service workers (4.76\%). These findings are similar to the study in south India ${ }^{11}$. Fungal keratitis was found mainly in farmers and then housewives in this study. The farmers are engaged in agricultural work, so they are prone to have ocular trauma especially by paddy, paddy leaves and other farming materials. Most of the patients $(77.55 \%)$ were from rural areas $(\mathrm{P}<0.001)$ and fungal corneal ulcer $(46.26 \%)$ was significantly higher in rural population than urban. Most of housewives of rural areas of 
Bangladesh work with paddy and other agricultural materials so they are also prone to have ocular injury by these materials.

Staphylococcus epidermidis and aureus are the most common causes of bacterial keratitis. Aspergillus species and Fusorium species are the leading causative agents of fungal keratitis. Corneal ulcers are common in middle aged men. Agricultural activity and related ocular trauma are the principal risk factors of corneal ulcer.

\section{References:}

1. Tananuvat N, Suwanniponth M. Microbial Keratitis in Thailand: a survey of common practice patterns. J Med Assoc Thai 2008; 91: 316-22.

2. Khan MU, Haque MR. Prevalence and Causes of Blindness in Rural Bangladesh. Ind J Med Res 1985; 82: 257-62.

3. Dunlop AA, Wright ED, Howlader SA, Nazrul I, Hussain R, Mcclellan K, Billson FA. Suppurative Corneal Ulceration in Bangladesh: A study of 142 Cases Examining The Microbiological Diagnosis, Clinical And Epidemiological Features of Bacterial And Fungal Keratitis. Aust N A J Ophthalmol 1994; 22(2): 105-10.

4. Akter L, Salam MA, Hasan B, Begum N, Ahmed I. Etiological agents of suppurative corneal ulcer: Study of 56 cases. Bangladesh J Med Microbiol 2009; 03(01):33-6.

5. Alexandrakis G, Alfanso EC, Miller D. Shifting trends in bacterial keratitis in South Florida and emerging resistance to Fluroquinolones. Ophthalmology 2000; 107: 1497-502.

6. Leck AK, Thomas PA, Hagan M, Kaliamurthy, Ackuaku E, John M, et al. Aetiology of suppurative corneal ulcers in Ghana and south India, and epidemiology of fungal keratitis. Br J Ophthalmol 2002; 86:1211-5.

7. Schaefer F, Bruttin O, Zografos L, Guex-Crosier Y. Bacterial keratitis: a prospective clinical and microbiological study. Br J Ophthalmol 2001; 875:842-7.

8. Sutphen JE, Pelugfelder SP, Wilhelmus KR, Jones DB. Penicillin Resistant Streptococcus Pneumoniae Keratitis. Am J Ophthalmol 1984; 97: 388-9.

9. Sharma S, Athmanathan S. Diagnostic procedures in infectious keratitis. In: Nema HV, Nema N, editors. Diagnostic procedures in ophthalmology. New Delhi: Jaypee Brothers Medical Publishers; 2002. 232-53.

10. Jones DB, Liesegang TJ, Robinson NM. Laboratory diagnosis of ocular infections. Washington DC: Cumitech 13, American Society for Microbiology; 1981.

11. Srinivasan M, Gonzales CA, George C, Cevallus V, Mascarenhas JM, Asokan B, et al. Epidemiology and aetiological diagnosis of corneal ulceration in Madurai, south India. Br J Ophthalmol 1997; 81:965-71.

12. Gopinathan U, Garg P, Fernandes M, Sharma S, Athmanathan S, Rao GN. The epidemiological features and laboratory results of fungal keratitis: A 10-year review at a referral eye care center in South India. Cornea 2002; 21:555-9.

13. Hagan M, Wright E, Newman M, Dolin P, Johnson G. Causes of suppurative keratitis in Ghana. $\mathrm{Br} \mathrm{J}$ Ophthalmol. 1995;79:1024-8.

14. Upadhyay MP, Karmacharya PC, Koirala S, Tuladhar N, Bryan LE, Smolint G, et al. Epidemiologic characteristics, predisposing factors, and etiologic diagnosis of corneal ulceration in Nepal. Am J Ophthalmol. 1991;111:92-9.

15. Chander J, Sharma A. Prevalence of fungal corneal ulcers in northern India. Infection. 1994;22:207-9.

16. Liesegang TJ, Forster RK. Spectrum of microbial keratitis in south Florida. Am J Ophthalmol. 1980;90:3847. 